\title{
An experimental study on the mechanical characteristics of low alloy carbon steels for better performance of traditional farm implements in Ethiopia
}

\author{
Belete Kefarge Azmite ${ }^{1, ~ *, ~ A d h e n a ~ A y a l i e w ~ W e r k n e h ~}{ }^{1}$, Asmamaw Tegegne Abebe ${ }^{2}$, Fekadu Gashaw \\ Hone $^{3}$ \\ ${ }^{1}$ Department of Chemistry, Collage of Natural and Computational Science, Jigjiga University, PO.Box: 1020, Jigjiga, Ethiopia \\ ${ }^{2}$ Department of Metallurgical and Materials Engineering, Defence Engineering University College, Bishoftu, Ethiopia \\ ${ }^{3}$ Department of Physics, Collage of Natural and Computational Science, Hawassa University, Hawassa, Ethiopia
}

\section{Email address:}

beletekefarge28@gmail.com (B. Kefarge)

\section{To cite this article:}

Belete Kefarge Azmite, Adhena Ayaliew Werkneh, Asmamaw Tegegne Abebe, Fekadu Gashaw Hone. An Experimental Study on the Mechanical Characteristics of Low Alloy Carbon Steels for Better Performance of Traditional Farm Implements in Ethiopia. International Journal of Materials Science and Applications. Vol. 3, No. 6, 2014, pp. 420-430. doi: 10.11648/j.ijmsa.20140306.31

\begin{abstract}
For most developing countries, including Ethiopia Agriculture is the backbone of their economy. Due to lack of effective farm implements, theses country's population has been suffering on food shortage. Hence, the major objective the study is to improve the mechanical properties and abrasion resistance of traditional farm implements. To achieve the intended objectives of the study, Investigation was conducted on the mechanical and wear characteristics of steel samples for better performance of farm implements subjected to packed carburization treatment using wood coal as the carburizer, carburized at $850{ }^{\circ} \mathrm{C}, 900{ }^{\circ} \mathrm{C}$ and $950{ }^{\circ} \mathrm{C}$, soaked at the carburizing temperature for $1: 50 \mathrm{hrs}$ followed by quenched with water. At the first the test specimen for analysis of different mechanical and wear characteristics of various local farming tools like abrasive wear, toughness, tensile strength, abrasive wear and hardness were prepared as per ASTM standard. The test specimens that was prepared for this purpose was subjected to destructive mechanical test before and after carburization process. From the data obtained, ultimate tensile strength, percent elongation, percent reduction in area, modulus of elasticity, Rockwell hardness, impact toughness, and abrasive wear were calculated. The destructive mechanical test results are compared before and after carburization process in order to see the impact of pack carburization and carburizing temperature on the performance (life cycle )of the traditional farm implements. It was observed that the mechanical properties of steel samples were found to be strongly influenced by the process of carburization, carburizing temperature and soaking time at carburizing temperature. It was concluded that the sample carburized at $950{ }^{\circ} \mathrm{C}$ soaked for $1: 50 \mathrm{hrs}$ followed by water quenching gives best result than the other samples. Since pack carburizing enhance the hardness, tensile strength, abrasion resistance, the farm implement manufacturing company has been recommended to carburize these farm implement.
\end{abstract}

Keywords: Abrasion Resistance, Hardness, Pack Carburization, Tensile Strength, Toughness

\section{Introduction}

According to ministry of agriculture of Ethiopia (2007), Agriculture is the backbone of economy for Ethiopia and a source of income for eighty five percent, $85 \%$ of the population. In spite of rapid growth in population of agricultural machineries, the level of mechanization in our country as a whole is still at a very low level. The main reasons for this are non-availability of high quality implements and lack of demonstration services for the popularization. During agricultural operation (plowing, digging, mowing, cultivating) the farm implements undergo abrasion by the scratching action of sand and stone particles present in the soil and it is the most common cause for damage and failure agricultural machineries. The dry land agriculture is dominant in Ethiopia and the wear and tear of tools/equipment's are more severe than in irrigated land. The reduction in the wear of farm implements will ensure the material and energy losses at a desired minimum level. In developing nations, the low and medium carbon steels are usually used to making farm implements because they are 
less expensive and easily machinable. However, some of the agro-industries use also costlier high carbon and low alloy steels for making agricultural tools. In view of the poor economic conditions of farmers, the farm implements made of cheaply and abundantly available mild and medium carbon steels are favorable for developing nations. Due to the limited resources and less technical knowledge, the agro-industries have not been able to substantially improve the hardness, tensile strength and wear resistance of these steels [ ].

Structures and machines, or their components, fail because of fracture or excessive deformation. In attempting to prevent such failure, the designer estimates how much stress (load per unit area) can be anticipated, and specifies materials that can withstand expected stresses. A stress analysis either accomplished experimentally or by means of a mathematical model, indicates expected areas of high stress in a machine .Mechanical property tests, carried out experimentally, indicate which materials may safely be employed [1].

Material testing is measurement of the characteristics and behavior of materials such as metals, ceramics, or plastics under various conditions. The data thus obtained can be used in specifying the suitability of materials for various applications such as building construction, aircraft construction, machinery, or packaging. A full or small-scale model of a proposed machine or structure may be tested. Alternatively, investigators may construct mathematical models that utilize known material characteristics and behavior to predict capabilities of the structure. Materials testing classifies into five major categories: mechanical testing; testing for thermal properties; testing for electrical properties; testing for resistance to corrosion, radiation, and biological deterioration; and nondestructive testing. Such national and international bodies have established standard test methods as the International Organization for Standardization (ISO), with headquarters in Geneva, and the American Society for Testing and Materials (ASTM), Philadelphia [2].

The traditional method of applying the carbon to the surfaces of the iron involved packing the iron in a mixture of ground bone or charcoal or a combination of leathers, hooves, salt and urine, all inside a well-sealed box. The resulting package is then heated to a high temperature, but still under the melting point of the iron and left at that temperature for a length of time. The longer the package is held at the high temperature, deeper carbon will diffuse into the surface, the resulting case hardened part may show a distinct correlation on the surface. Carburizing is a process of adding carbon to surface. This is done by exposing the part to carbon rich atmosphere at the elevated temp (nearly melting point) and allows diffusion to transfer the carbon atoms in the steel [3]. Carburizing is one of the most commonly performed steel heat treatments. For perhaps three thousand years, it was performed by packing the mild and low carbon steel parts in charcoal, then raising the temperature of the pack to red heat for several hours. The entire pack, charcoal and all, was then dumped into water to quench it. The surface became very hard, while the interior or "core" of the part retained the toughness of low carbon steel [4].

Carburizing is one of the most widely used surface hardening processes. The process involves diffusing carbon into a low carbon steel alloy to form a high carbon steel surface. Because of these parts are generally subjected to high load and impact, Carburizing steel is widely used as a material of automobiles, farm implements, machines, gears, springs, and high strength wires etc., which are required to have the excellent strength, toughness, hardness and wear resistance, etc. Such mechanical properties and wear resistance can be obtained from the carburization and quenching processes. This manufacturing process can be characterized by the key points such as it is applied to low carbon work pieces, work pieces are in contact with high carbon gas, liquid or solid, it produces hard work piece surface, work piece cores retain soft[5].

Carburization provides a gradual change in carbon content and carbide volume from the surface to the bulk, resulting in a gradual alteration of mechanical and wear properties of the material. The heat treatment and carburization increases the mechanical and wear resistance of the material In general, carburizing is the addition of carbon to the surface of low carbon steels at temperatures generally between 850 and $950{ }^{\circ} \mathrm{C}\left(1560\right.$ and $\left.1740{ }^{\circ} \mathrm{F}\right)$ at austenite region that had high solubility for carbon and the stable crystal structure. Hardening is accomplished when the high carbon surface layer is quenched to form martensite so that a high carbon martensitic case will have good wear and fatigue resistance [4]. Carburizing steels for case hardening usually have base carbon contents of about $0.2 \%$, with the carbon content of the carburized layer generally being controlled at between 0.8 and $1 \% \mathrm{C}$. However, surface carbon is often limited to $0.9 \%$ because too high a carbon content can result in retained austenite and brittle martensite. In addition, Carburizing process increases the grains size due to permanence for a long time in the austenitic region of the phase diagram, and makes necessary a posterior heat treatment to refine the grains. Classic quenching generates a martensitic hard but brittle material. On the other hand, inter critical quenching transforms the outward carbon rich solid solution into martensite, while the internal microstructures present a mixture of martensite, producing a less-brittle material [5].

\section{Material and Method}

\subsection{Material Selection}

Locally available wood coal was selected due to its low cost and easy availability in the country. About $6 \mathrm{~kg}$ of coal was purchased from the local market, it is crushed with the help of crusher, test sample is prepared, and this coal is used for the pack carburization of steel samples. Steel samples used for this experimental work were taken from Kotebe metal tools factory (K.M.T.F). All samples are taken from each agricultural tool produced in the factory and the test specimens were prepared from each materials included in the 
Table 1. The various farming tools used in the study with the chemical composition.

\begin{tabular}{|c|c|c|c|c|c|c|}
\hline \multirow{2}{*}{ Sample no } & \multirow{2}{*}{ Farming tool } & \multicolumn{5}{|c|}{ Chemical composition (wt \%) } \\
\hline & & C & Mn & $\mathbf{S i}$ & $\mathbf{P}$ & $\mathbf{S}$ \\
\hline 1 & Shovel, Spade ,Harar and Hoe & $0.38-0.49$ & $0.5-0.8$ & $0.15-0.35$ & 0.05 & 0.05 \\
\hline 3 & Machete, Chisel and Crowbars & $0.38-0.49$ & $0.5-0.8$ & $0.15-0.8$ & 0.05 & 0.05 \\
\hline
\end{tabular}

Source: K.M.T.F

\subsection{Preparation of Test Specimens}

The first and foremost job for the experiment is specimen preparation. The specimen size should be compatible to the machine specifications. So the test specimen for analysis of different mechanical and wear characteristics of various local farming tools like abrasive wear, toughness, tensile strength, and hardness were prepared as per ASTM standard.

\subsubsection{Specimen for Hardness Test}

The hardness test specimens were prepared as per ASTM standard. A standard specimen of dimensions $(4 \mathrm{~cm} \times 2.5 \mathrm{~cm}$ $\mathrm{x} 0.5 \mathrm{~cm}$ ) of steel is prepared in order to study the hardness characteristics of each farm implements.
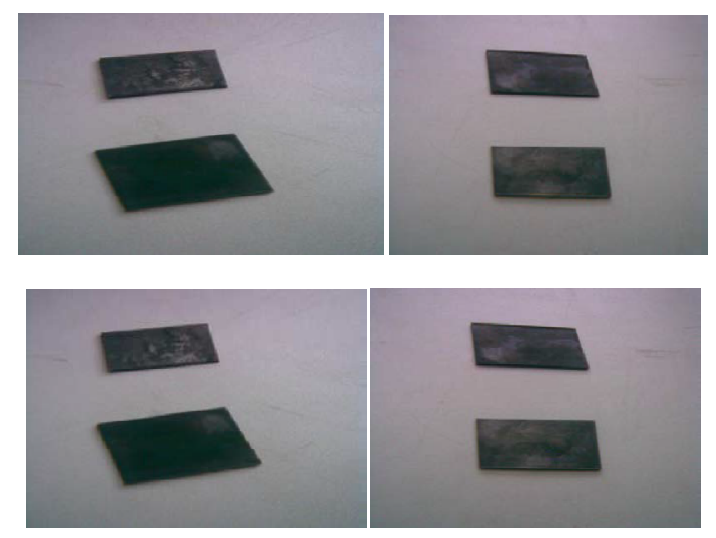

Fig. 1. Steel Specimen for hardness test.

\subsubsection{Specimen for Toughness Test}

A toughness test specimen as per ASTM standard is prepared in order to study the resistance of a material to sudden fracture, where a sharp stress raiser or a flaw is present. In these tests, the energy required to produce rupture is determined to exhibit relative tendency of brittleness. The standard specimens prepared for this purpose have the following dimensions.

Table 2. Specimen dimension for toughness test.

\begin{tabular}{ll}
\hline Length & $\mathbf{5 . 5} \mathbf{~ c m}$ \\
\hline Width & $1 \mathrm{~cm}$ \\
Thickness & $1 \mathrm{~cm}$ \\
Notch depth & $0.5 \mathrm{~cm}$ \\
\hline
\end{tabular}
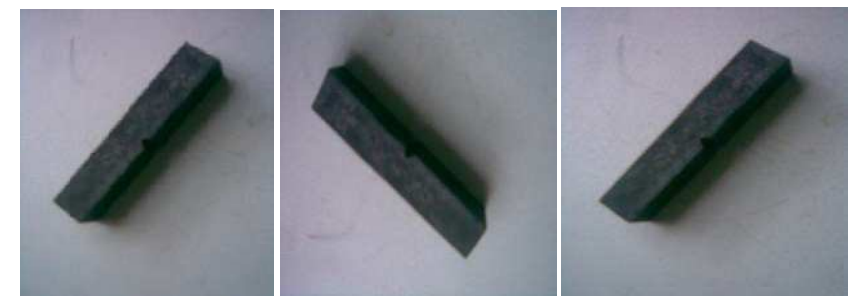

Fig. 2. Steel Specimen for toughness test.

\subsubsection{Specimen for Tensile Strength Test}

A tensile test specimen as per ASTM standard is prepared in order to determine ultimate tensile strength, modulus of elasticity, Percentage reduction in the cross sectional area, Percentage elongation and The fracture point. The standard specimens prepared for this purpose have the following dimensions Working edge length (lo) $=55 \mathrm{~mm}$, Working edge diameter $(\mathrm{do})=5 \mathrm{~mm}$.
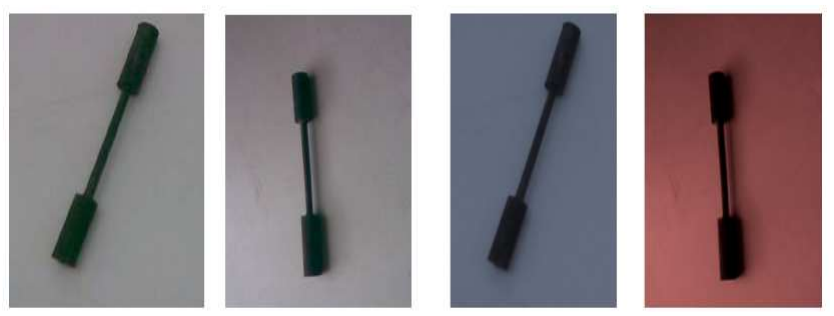

Fig. 3. Steel Specimen for tensile strength test.

\subsubsection{Specimen for Abrasive Wear Test}

A abrasion test specimen as per ASTM standard and the standard specimen of dimensions $(4 \mathrm{~cm} \times 2.5 \mathrm{~cm} \times 0.5 \mathrm{~cm})$ of steel is prepared in order to study the hardness characteristics of each the traditional farm implements.
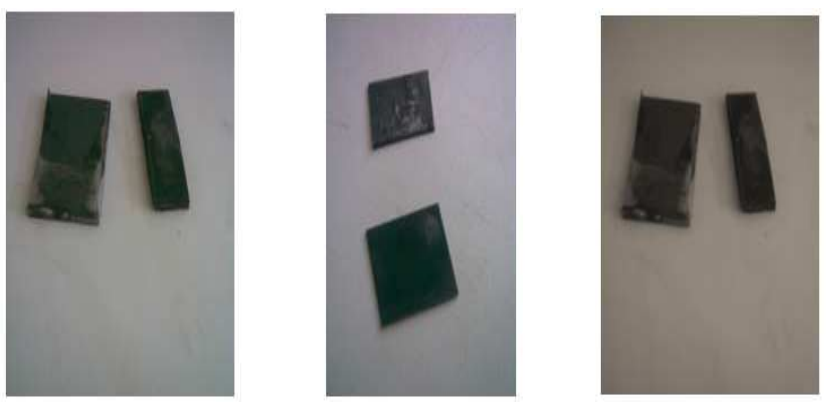

Fig. 4. Abrasive wear test specimens (Steel). 


\subsection{Carburization of Steel Samples}

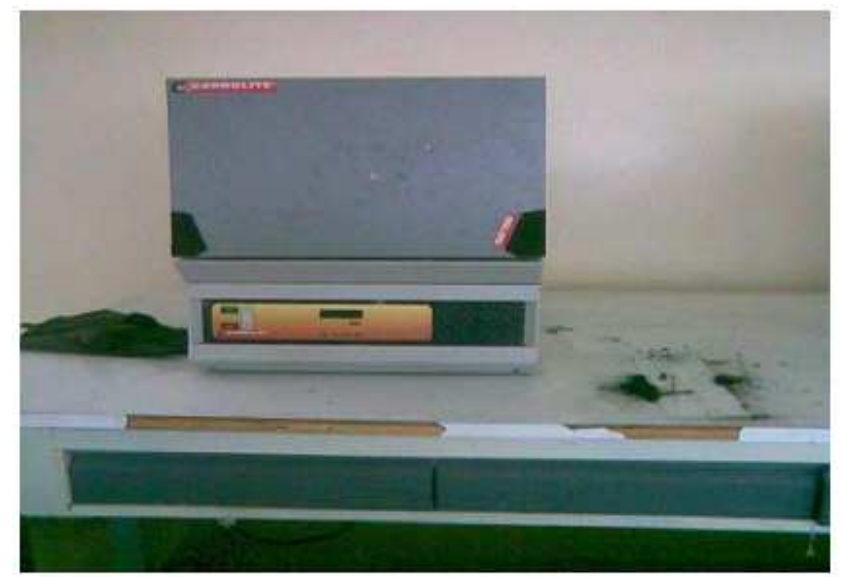

Fig. 5. Electrical furnace for carburization of steel samples.

The different test specimen samples made up of steel for the mechanical and wear characteristics testing were subjected to pack carburization treatment. In this process the steel samples were placed on the thick bed of carburizer kept in a stainless steel container and fully covered from all sides, the top of the container was covered with a steel plate. The container was then introduced into the Electrical furnace and then maintained at the different required carburization temperatures of 850,900 and $950{ }^{\circ} \mathrm{C}$ with the soak time of 1:50 hours and then they were quenched in water. Then the carburized and quenched steel specimens are then subjected to various kind of mechanical and wear test.

\subsection{Study of Destructive Mechanical Testing}

A destructive Mechanical test (as opposed to nondestructive mechanical types of tests) often involves the deformation or breakage of samples of material called test specimens or test pieces. As the objective of the project is to study the mechanical and wear characteristics of various carburized and tempered steel samples for better performance of traditional farm implements, now the carburized and quenched steel specimens were subjected to various destructive mechanical tests.

\subsubsection{Hardness Testing}

Rockwell hardness testing is a general method for measuring the bulk hardness of metallic and polymer materials. Although hardness testing does not give a direct measurement of any performance properties, hardness correlates with strength, wear resistance, and other properties. Rockwell hardness testing is widely used for material evaluation due to its simplicity and low cost relative to direct measurement of many properties. Rockwell hardness testing method is the most widely used hardness-testing method and generally accepted due to its speed, freedom from personal error, ability to distinguish small hardness difference, so simple to perform and require no special skills [20]. In present experimental work the hardness of the carburized steel samples that are carburized under different temperature range of 850,900 and $950{ }^{0} \mathrm{C}$ measured by means of Rockwell hardness tester. The procedure carried out in determining the Rockwell testing can be listed as follows:

- First, the diamond indenter was inserted in the machine and the load is adjusted to $100 \mathrm{~kg}$.

- The minor load of a $10 \mathrm{~kg}$ was first applied to seat of the specimen.

- Then the major load applied and the depth of indentation is automatically recorded on a dial gage in terms of arbitrary hardness numbers.

The dial contains 100 divisions. Each division corresponds to a penetration of $0.002 \mathrm{~mm}$. The dial is reversed so that a high hardness, which results in small penetration, results in a high hardness number. Removal of the additional major load allows a partial recovery, so reducing the depth of penetration. The permanent increase in depth of penetration, resulting from the application and removal of the additional major load is used to calculate the Rockwell hardness number. For each of the sample, test was conducted for three times and the average of all the samples was taken as the observed values in each case.

\subsubsection{Tensile Strength Testing}

The tensile test is used to determine the ductility and the toughness of a material. Ductility refers to the ability of a material to deform plastically, or permanently, without breaking when stresses are applied. The amount of deformation that occurs before fracture is a measure of the material's ductility. It is quantified by the percent elongation and the percent reduction in area. Toughness is the ability to withstand stresses before breaking and is quantified by measuring the area under the stress-strain curve. Brittle materials tend to be relatively strong, but do not stretch. Ductile materials will stretch, but are relatively weak. In present experiment the carburized and quenched steel specimens which are treated under different temperature range of 850,900 and $950{ }^{\circ} \mathrm{C}$ were treated with in a tensile testing machine and the percent elongation, ultimate tensile strength, percent reduction in area and Young's modulus of elasticity were calculated by using the formula.

$$
\text { Percent elongation }(\% \text { elongation })=\frac{L f-L o}{L o} \mathrm{X} 100
$$

Where, Lf is final length of the specimen, Lo is initial length for the specimen.

$$
\text { Ultimate tensile strength }=\frac{P}{A_{O}}
$$

Where $\mathrm{P}$ is the maximum load applied on the specimen, and Ao is the initial cross-sectional area.

$$
\text { Yield strength }=\frac{\text { load at } 0.2 \% \text { offset yield }}{\text { Ao }}
$$

Where: Ao is the original cross-sectional area of the specimen.

$$
\text { Percent reduction in area }=\frac{\text { Ao- } \mathrm{Af}}{\text { Ao }} \text { X } 100
$$


Where Ao is the original cross-sectional area and $A_{f}$ is the cross-sectional area at the point of fracture.

It can be observed that as the load increases the specimen initially gets elastically elongated. On further elongation, the specimen starts necking at some points when the material goes beyond the elastic range. The reduced width of specimen would further be reduced under the force of the load and finally develops fractures when the test is completed. And also there is a limit up to which the applied stress is directly proportional to the induced strain, the end of this linear portion is the yield point of the material above which the material starts plastically deforming and when the force applied load goes beyond the limit that can borne by the material, the specimen breaks. The stress at elastic limit is called yield strength. The maximum stress reached in a material before the fracture is termed as the ultimate tensile strength.
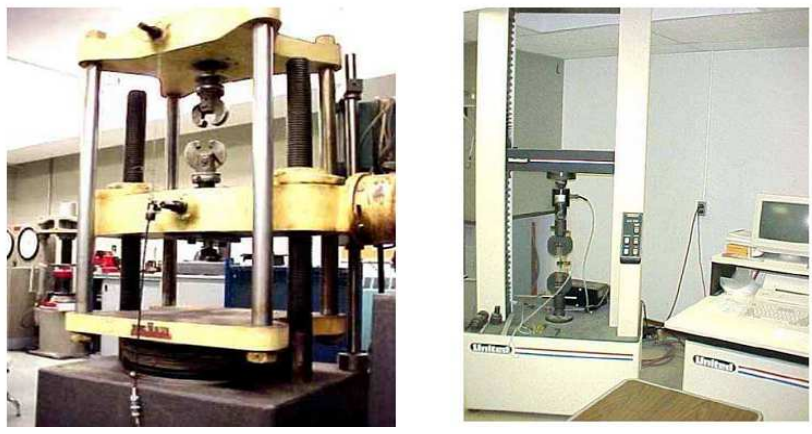

Fig. 6. Universal testing machine (WP310).

\subsubsection{Toughness (Charpy Impact) Testing}

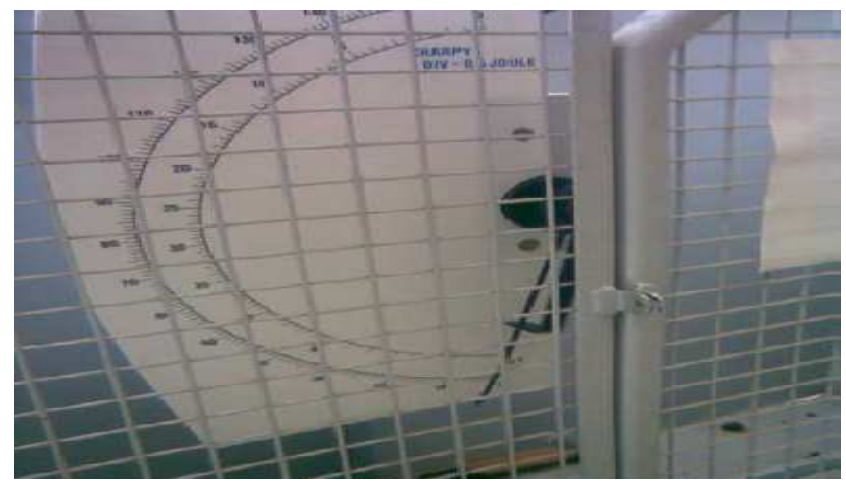

Fig. 7. Charpy impact tester for toughness testing (T50).

Toughness is defined as the ability of a material to absorb energy. When a material is loaded quickly or shocked or impacted, its behavior is, in many cases, different from the behavior exhibited in the tensile test, where the load is applied slowly. Whether shocks occur as part of normal service or by accident, the impact strength of the material will determine its suitability for a particular use. Any tendency of a material toward brittle behavior can be demonstrated through the impact test. The impact test measures the amount of energy absorbed by the material before it fractures. A tough material will absorb more energy than a brittle one.
In present experimental work Charpy, impact test were carried out on the carburized and quenched steel specimens, which have been treated under different temperature range of 850,900 and $950{ }^{\circ} \mathrm{C}$ under a Charpy impact tester $\left(\mathrm{T}_{50}\right)$ for the assessment of brittle fracture of the mild steel. The test was performed on each of the sample three times and the average of all the samples was taken as the observed values in each case.

\subsection{Abrasive Wear Testing}

The materials that are prepared for this experiment is uncarburized and carburized steel samples that is carburized under different temperature range with dimensions $4.0 \mathrm{~cm} \mathrm{x}$ $2.5 \mathrm{~cm} \times 0.5 \mathrm{~cm}$. The abrasive wear test were conducted on each of the samples before and after carburization (at a temperatures of 850,900 and $950{ }^{\circ} \mathrm{C}$ ) in order to study the abrasive wear resistance of traditional farm implements by using abrasive file having different grades, rough, medium and soft file this is due to lack of modern testing machine. The sample was mounted perpendicularly on a disc such that its one of the face is forced to press against the abrasive file then it tends to wear the surface of the samples at this time the weight loss was observed.

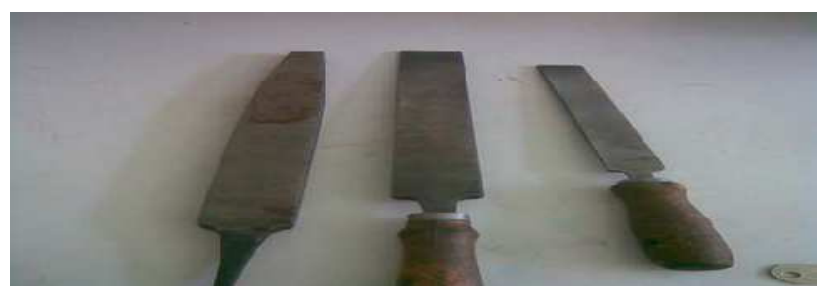

Fig. 8. Abrasive file used for wear test (left to right rough (double cut), medium (double cut) and soft (single cut)).

\section{Result and Discussion}

In the present work, to study the mechanical and wear characteristics of the traditional farm implements and to minimize their quick failure and damage by pack carburization process the sample were taken from Kotebe metal tools factory (K.M.T.F). In the study, the 11 traditional farm implements mechanical and characteristics were studied. The mechanical and wear properties of the traditional farm implements that were studied. The hardness properties tested by using Rockwell hardness tester, the tensile properties i.e. ultimate tensile strength, percent elongation, percent reduction in area and modulus of elasticity by universal tensile testing machine, the impact (toughness) by using charpy impact testing machine and the abrasive wear properties by using abrasive file having different grades.

In general, from the experiment, we can saw that heat treatment and carburization of steel samples increases the hardness, tensile strength and wear resistance and decreases toughness values. The tests results of different mechanical properties like hardness, tensile strength, toughness and abrasion resistance under different carburization temperature of 850,900 and $950{ }^{\circ} \mathrm{C}$ is discussed in detail 


\subsection{Effect of Carburizing Temperature on the Hardness Properties of the Carburized Steel Samples}

The hardness values of the simple, carburized and tempered mild steel samples, which are carburized under different temperature range of 850,900 and $950{ }^{\circ} \mathrm{C}$, measured by means of Rockwell hardness tester and the test results are described as follow.

Table 3. The average Rockwell hardness number of each farming tool before carburization and after carburization.

\begin{tabular}{|c|c|c|c|c|}
\hline & & & Hardness number & \\
\hline \multirow{4}{*}{ Before carburization } & Sample & Type of indenter & HRD (load applied=100 kg) & HRC (load applied=150 kg) \\
\hline & Sample 1 & Diamond point & 0 & Out of range \\
\hline & Sample 2 & Diamond point & 49.95 & Out of range \\
\hline & Sample 3 & Diamond point & 19.11 & Out of range \\
\hline \multirow{3}{*}{ Carburized at $8500 C \&$ soaked for $1.50 \mathrm{hr}$} & Sample 1 & Diamond point & 31.25 & Out of range \\
\hline & Sample 2 & Diamond point & 66.25 & Out of range \\
\hline & Sample 3 & Diamond point & 35.41 & Out of range \\
\hline \multirow{3}{*}{ Carburized at $9000 \mathrm{OC} \&$ soaked for $1.50 \mathrm{hr}$} & Sample 1 & Diamond point & 34.18 & 0 \\
\hline & Sample 2 & Diamond point & 73.49 & 69.15 \\
\hline & Sample 3 & Diamond point & 49.44 & 42.60 \\
\hline \multirow{3}{*}{ Carburized at $950 \mathrm{OC} \&$ soaked for $1.50 \mathrm{hr}$} & Sample 1 & Diamond point & 45.52 & 25.5 \\
\hline & Sample 2 & Diamond point & 80.28 & 69.4 \\
\hline & Sample 3 & Diamond point & 45.25 & 52.73 \\
\hline
\end{tabular}

From the above table it is noted that the hardness values of sample 1 is varied between ranges from 0-45.52 in HRD scale. The highest hardness number was recorded for this sample which is carburized at $950{ }^{\circ} \mathrm{C}$ and quenched for 1:50 hours and also the lowest hardness number was recorded for sample which is Carburized at $850{ }^{\circ} \mathrm{C}$ and quenched for 1:50 hours.

The hardness values of sample 2 is varied between 49.95 80.28 in HRD scale and the highest hardness number was recorded for this sample which is carburized at $950{ }^{\circ} \mathrm{C}$ and quenched for 1:50 hours and also when we see the sample after carburization the lowest hardness number was recorded for sample which is Carburized at $850{ }^{\circ} \mathrm{C}$ and quenched for 1:50 hours. The hardness values of sample 2 is varied between 19.11-55.25 in HRD scale and the highest hardness number was recorded for this sample which is carburized at $950{ }^{\circ} \mathrm{C}$ and quenched for 1.50 hours and also when we see the sample after carburization the lowest hardness number was recorded for sample which is Carburized at $850{ }^{\circ} \mathrm{C}$ and quenched for 1:50 hours.

Generally ,For all samples the highest hardness number value was recorded for the samples which is carburized at $950{ }^{\mathrm{O}} \mathrm{C}$ and quenched for 1:50 hours and also the lowest hardness number was recorded for sample which is Carburized at $850{ }^{\circ} \mathrm{C}$ and quenched for 1:50 hours, from this we can observe that as the carburizing temperature increases the hardness number also increases. From the hardness test result it is also noted that the hardness values of uncarburized steel sample is unable to test in HRC scale this is because the material has very low hardness value. we can see that as the carburizing temperature increases the hardness number also increases, this phenomena is shown graphically below (fig. 9). For sample one and sample three when the carburization temperature becomes $900{ }^{\mathrm{O}} \mathrm{C}$ and $950{ }^{\circ} \mathrm{C}$ even the hardness scales of the sample were improved (from HRD scale to HRC scale).

From the fig 9 above, It is notice that as the carburization temperature increases the hardness value of the different farm implements also increased and also the best result was recorded for the materials that was carburized at $950{ }^{\circ} \mathrm{C}$, so the hardness of the farming tools were improved by the carburization process this phenomenon was supported from much of the literature. From the hardness test, experiment it is also noted that the hardness values of uncarburized sample is unable to calculate in HRC scale because of its very less hardness values.

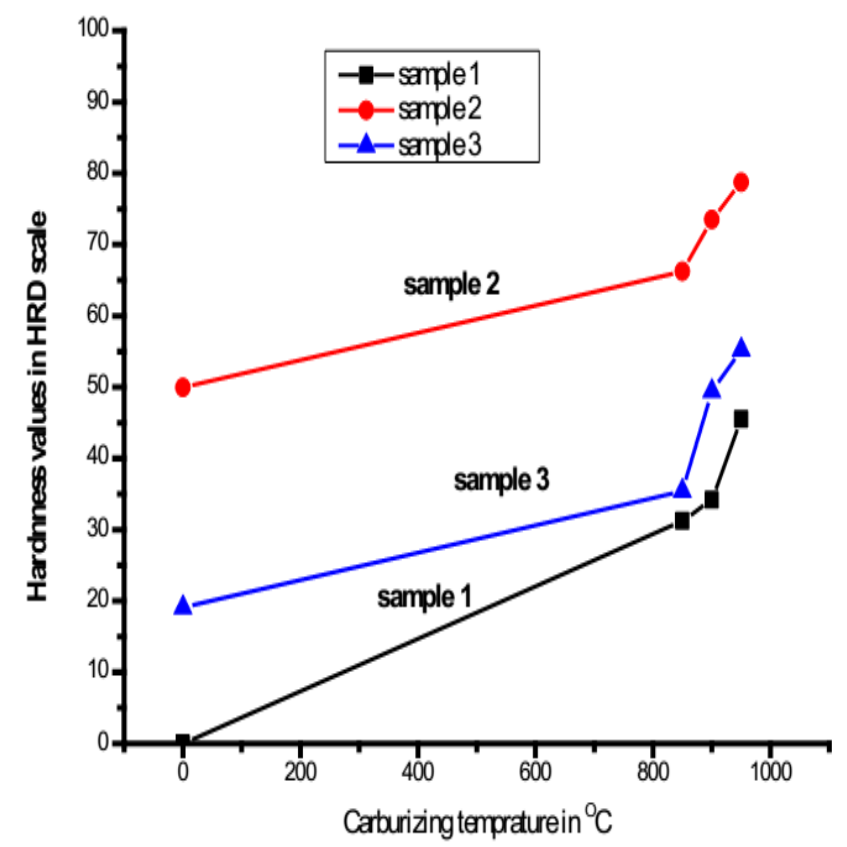

Fig. 9. Variation of Rockwell hardness number with the carburization temperature for different samples.

\subsection{Effect of Carburizing Temperature on the Tensile Properties of the Carburized Steel Samples}

The effect of carburizing temperature on the tensile 
properties of carburized and tempered mild steel is summarized in table 4.

Table 4. Tensile property test results of steel samples before and after carburization.

\begin{tabular}{|c|c|c|c|c|c|}
\hline \multirow[b]{2}{*}{ Time of testing } & \multirow[b]{2}{*}{ Sample } & \multicolumn{4}{|l|}{ Tensile properties } \\
\hline & & Percent elongation (\%) & $\begin{array}{l}\text { Ultimate tensile strength } \\
\left(\mathrm{N} / \mathrm{mm}^{2}\right)\end{array}$ & $\begin{array}{l}\text { Percent reduction } \\
\text { in area }(\%)\end{array}$ & $\begin{array}{l}\text { Modulus of elasticity } \\
\text { (in } \mathbf{N} / \mathbf{m m}^{2} \text { ) }\end{array}$ \\
\hline \multirow{3}{*}{ Before carburization } & Sample 1 & 18.2 & 480.2 & 68.6 & 2667.78 \\
\hline & Sample 2 & 27.2 & 555.64 & 64 & 2057.93 \\
\hline & Sample 3 & 25.45 & 550.32 & 53.76 & 2201.28 \\
\hline \multirow{3}{*}{$\begin{array}{l}\text { Carburized at } 850{ }^{\circ} \mathrm{C} \\
\text { \& soaked for } 1.50 \mathrm{hr}\end{array}$} & Sample 1 & 27.2 & 911.86 & 80.6 & 3377.26 \\
\hline & Sample 2 & 36.4 & 1055.12 & 75 & 2930.89 \\
\hline & Sample 3 & 34.6 & 1045.02 & 64 & 3020.29 \\
\hline \multirow{3}{*}{$\begin{array}{l}\text { Carburized at } 900{ }^{\circ} \mathrm{C} \\
\text { \& soaked for } 1.50 \mathrm{hr}\end{array}$} & Sample 1 & 38.2 & 957.83 & 84 & 2520.61 \\
\hline & Sample 2 & 47.3 & 1108.31 & 80.6 & 2358.11 \\
\hline & Sample 3 & 45.5 & 1097.70 & 66.4 & 2412.53 \\
\hline \multirow{3}{*}{$\begin{array}{l}\text { Carburized at } 950{ }^{\circ} \mathrm{C} \\
\text { \& soaked for } 1.50 \mathrm{hr}\end{array}$} & Sample 1 & 49.1 & 983.76 & 85.6 & 2007.67 \\
\hline & Sample 2 & 58.2 & 1138.31 & 84 & 1962.60 \\
\hline & Sample 3 & 56.4 & 1127.41 & 75 & 1998.95 \\
\hline
\end{tabular}

From the above table on all the carburization condition tested, it is readily apparent that the ultimate tensile strength, percent elongation, percent reduction in area and the tensile strength increased with increasing carburizing temperature for all samples. This result is in agreement with much of the existing literature, which indicates an approximately linear relationship between all the tensile properties and the carburizing temperature. The values of percent elongation for sample one is varied between the ranges of $18.2 \%-49.1 \%$, for sample two $27.2 \%-58.2 \%$, for sample three $25.45 \%$ $56.4 \%$. It is notice that the highest values of percent elongation result were recorded for each of the samples that was carburized at $950{ }^{\circ} \mathrm{C}$.

The ultimate tensile strength of sample one is varied in a range between $480.2 \mathrm{~N} / \mathrm{mm}^{2}-983.76 \mathrm{~N} / \mathrm{mm}^{2}$, for sample two $555.64 \mathrm{~N} / \mathrm{mm}^{2}-1138.31 \mathrm{~N} / \mathrm{mm}^{2}$ and for sample three 550.32 $\mathrm{N} / \mathrm{mm}^{2}-1127.41 \mathrm{~N} / \mathrm{mm}^{2}$. In addition, we can observe that for each of the samples the highest ultimate tensile strength value was recorded for the sample that was carburized at 950 ${ }^{0} \mathrm{C}$ and the lowest value was recorded for the uncarburized sample. The percent reduction in area of sample one is varied in a range between $68.6 \%-85.6 \%$, for sample two $64 \%-84 \%$, and for sample three $53.76 \%-75 \%$. In addition, we can observe that for each of the samples the highest percent reduction in area value was recorded for the sample that was carburized at $950{ }^{\circ} \mathrm{C}$ and the lowest value was recorded for the uncarburized sample.

The Modulusof elasticity of sample one is varied in a range between $2007.67 \mathrm{~N} / \mathrm{mm}^{2}-2667.78 \mathrm{~N} / \mathrm{mm}^{2}$, for sample two $1962.60 \mathrm{~N} / \mathrm{mm}^{2}-2057.93 \mathrm{~N} / \mathrm{mm}^{2}$ and for sample three $1998.95 \mathrm{~N} / \mathrm{mm}^{2}-2201.28 \mathrm{~N} / \mathrm{mm}^{2}$. In addition, we can observe that for each of the samples the highest Modulus of elasticity value was recorded for the uncarburized samples and the lowest value was recorded for the samples, which is carburized at $950{ }^{\circ} \mathrm{C}$. All the results that were obtained from the tensile property testing show that the carburization process greatly improved the tensile properties of farm implements. The effect of carburizing temperature on the percent elongation of each sample is shown below (fig. 10).

From fig 10, it is observed that the carburization temperature and the percent elongation of each sample have linear relationship and it is notice that the best result is obtained from the steel samples that were carburized at 950 ${ }^{\mathrm{O}} \mathrm{C}$ in each case.

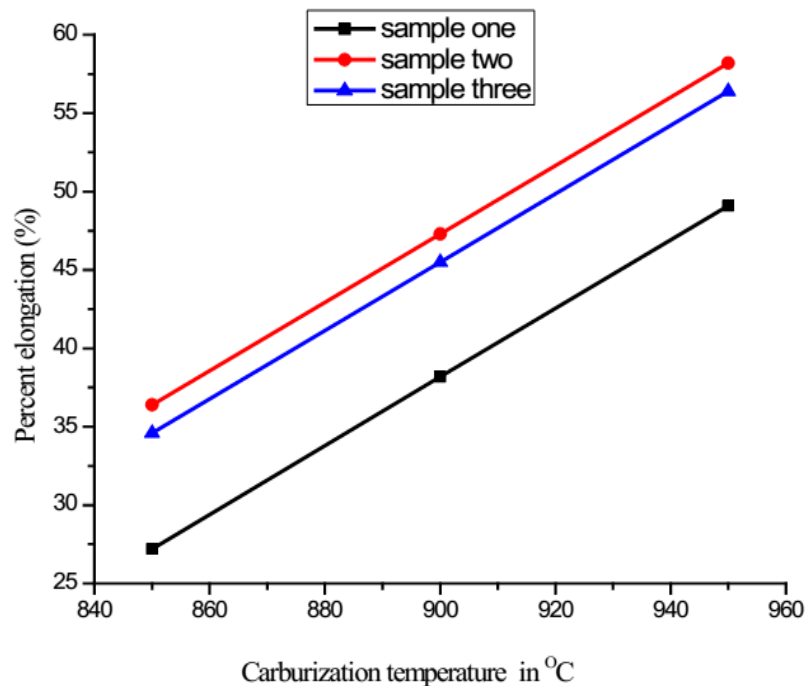

Fig. 10. The percent elongation vs. carburizing temperature for each of the samples.

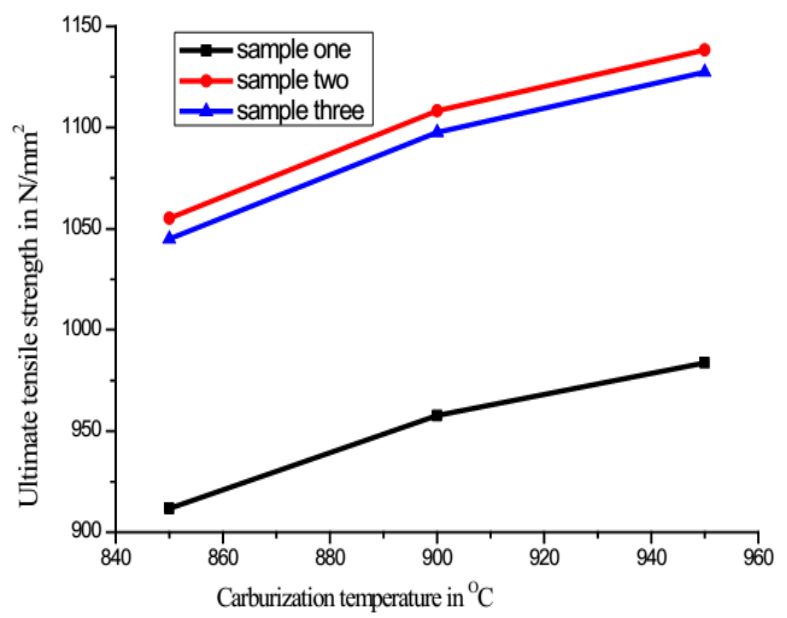

Fig. 11. Ultimate tensile strength vs. carburizing temperature. 


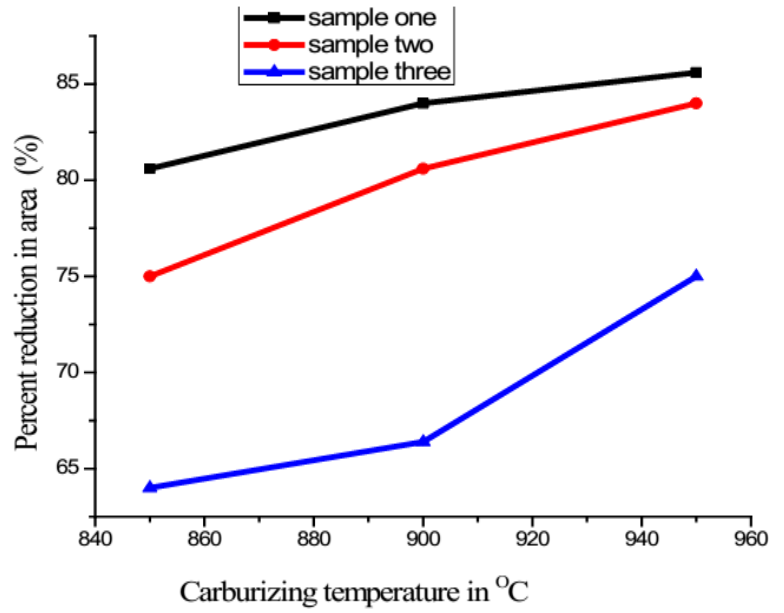

Fig. 12. Percent reduction in area vs. carburizing temperature.

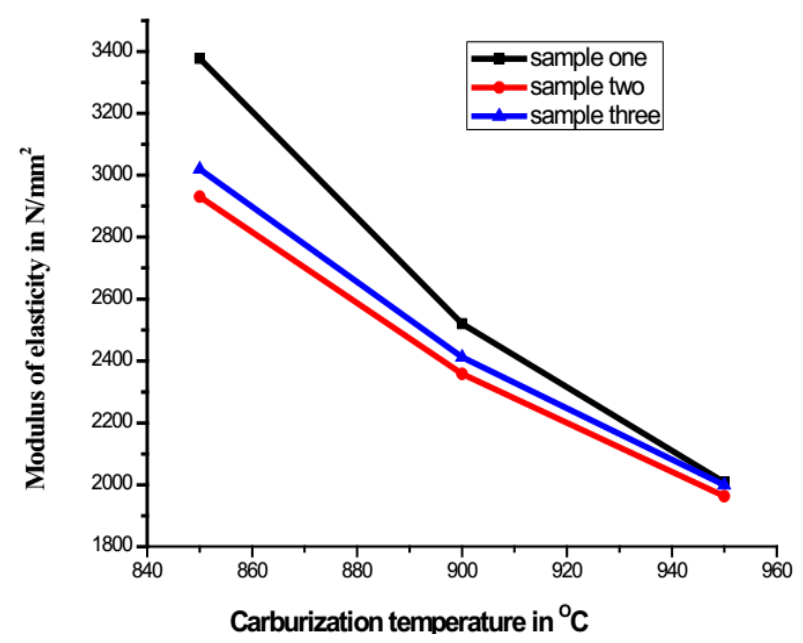

Fig. 13. Modulus of elasticity vs. carburizing temperature.

Figure 11 shows that as the carburization temperature increase ultimate tensile strength also increased this indicates the carburization temperature and ultimate tensile strength has a linear relationship and the best result is obtained from the steel samples that were carburized at $950{ }^{\circ} \mathrm{C}$ in each case.

Figure 12 shows that as the carburization temperature increase percent reduction in area also increased this indicates the carburization temperature and percent reduction in area has linear relationships and the best result is obtained from the steel samples that were carburized at $950{ }^{\circ} \mathrm{C}$ in each case.

Figure 13, shows that as the carburization temperature increase the modulus of elasticity decreases this indicates the carburization temperature and modulus of elasticity has an inverse relationship.

For all steel samples, it is notice that the highest values of percent elongation, ultimate tensile strength, percent reduction in area, and Modulus of elasticity results were recorded. For the samples that was carburized at $950{ }^{\circ} \mathrm{C}$ and the lowest result for the uncarburized sample, that lead to the conclusion that with the increase in the carburization temperature, the tensile properties of the carburized samples also increased.
Generally, all the results that were obtained from the tensile property testing show that the carburization process greatly improve the tensile properties of the traditional farm implements the result are also expected and supported from the existing literature [50].

\subsection{Effect of Carburization Temperature on Toughness Properties of Carburized Steel Samples}

The toughness properties of steel samples are highly influenced by the carburization process. The effect of carburizing temperature on the toughness properties of carburized and uncarburized steel samples is summarized in table 5 below

From the table 5 below, it is observed that the absorbed (impact) energy of sample one is varied in a range between $61 \mathrm{~J}-23 \mathrm{~J}$, for sample two $42 \mathrm{~J}-20 \mathrm{~J}$ and for sample three $54-22$ J. From this result, it observed that as the carburization temperature increases the impact (absorbed) energy of the steel samples become decreased, the lowest impact energy was recorded from the samples that was carburized at $950{ }^{\circ} \mathrm{C}$ and soaked for 1:50 hours and the highest value from the uncarburized steel samples.

Table 5. The effect of carburizing temperature on the impact energy of the samples.

\begin{tabular}{llll}
\hline Time of testing & Sample & Medium & Toughness in J \\
\hline Before & Sample 1 & Room temperature & 61 \\
carburization & Sample 2 & Room temperature & 42 \\
& Sample 3 & Room temperature & 54 \\
Carburized at 850 & Sample 1 & Room temperature & 43 \\
${ }^{\circ}$ C \& soaked for & Sample 2 & Room temperature & 35 \\
1.50 hr & Sample 3 & Room temperature & 37 \\
Carburized at 900 & Sample 1 & Room temperature & 32 \\
${ }^{\circ}$ C \& soaked for & Sample 2 & Room temperature & 24 \\
1.50 hr & Sample 3 & Room temperature & 27 \\
Carburized at 950 & Sample 1 & Room temperature & 23 \\
${ }^{\circ}$ C \& soaked for & Sample 2 & Room temperature & 20 \\
1.50 hr & Sample 3 & Room temperature & 22 \\
\hline
\end{tabular}

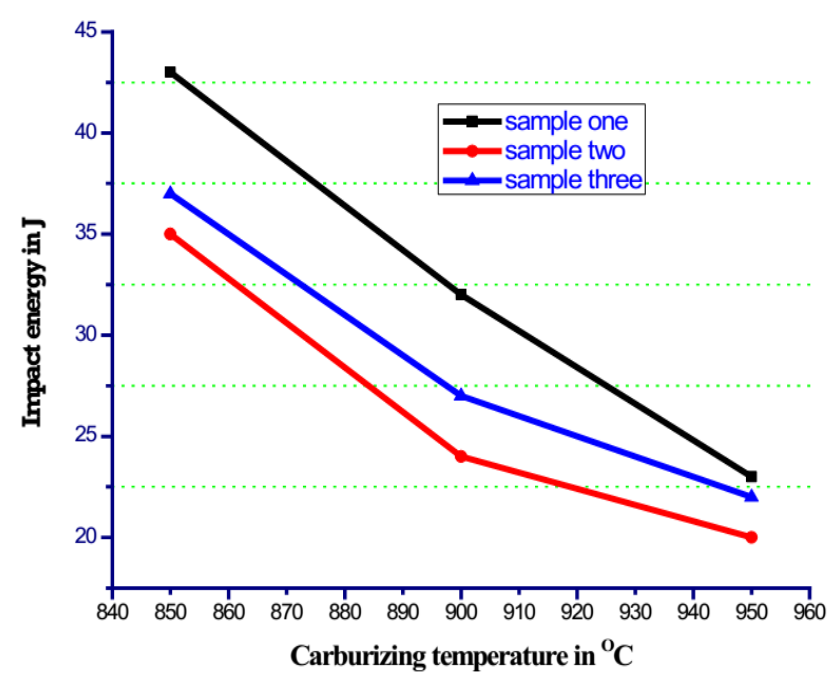

Fig. 14. Impact energy vs. carburizing temperature for different samples. 
As it has been shown in table 5, the toughness properties of mild steel is highly influenced by the carburization temperature. now it is noted that the toughness values of uncarburized steel samples is higher than that of carburized steel samples and toughness values decreases with increase in carburization temperature, so the process of carburization decreases the toughness of steel samples. This result is also shown graphically in the fig.14. This shows that with increase in the carburization temperature the toughness of carburized steel samples decreases.

From the table 6 we can observed that the abrasive properties of steel samples are highly improved by the carburization process. As the carburizing temperature increases the abrasion resistance also increased and the best result were obtained for the steel samples that was carburized at $950{ }^{\circ} \mathrm{C}$ and the lowest abrasion resistivity were observed for the uncarburized steel samples. The effect of carburization temperature on the abrasive wear resistance of the steel samples is shown graphically below (fig.15).

Generally, from this, it is concluded that the carburization process decreases absorbed (impact) energy of the samples. This result is expected and it is supported from the literature [21].

\subsection{Effect of Carburization Temperature on Abrasive Properties of Carburized Steel Samples}

The abrasive wear test were conducted on each of the samples before and after carburization (at a temperatures of 850,900 and $950{ }^{\circ} \mathrm{C}$ ) in order to study the abrasive wear resistance of traditional farm implements by using abrasive file having different grades this is due to lack of modern testing machine. The test results are explained qualitatively by observing the abrasion action of different abrasive file on each steel samples before and after carburization. The abrasion action of each abrasive file on each of the uncarburized and carburized steel samples, which are carburized under different temperature range of 850, 900 and $950{ }^{\circ} \mathrm{C}$, measured by different abrasive files having different grade and the test results are described as follow

Table 6. The abrasive wear results for the carburized and uncarburized steel samples.

\begin{tabular}{lll}
\hline Time of testing & Type of abrasive file & Abrasive result \\
\hline \multirow{3}{*}{ Before carburization } & Rough file & 7 \\
& Medium file & 6 \\
& Smooth file & 5 \\
Carburized at $850^{\circ} \mathrm{C} \&$ soaked for $1.50 \mathrm{hr}$ & Rough file & 5 \\
& Medium file & 4 \\
Carburized at $900^{\circ} \mathrm{C} \&$ soaked for $1.50 \mathrm{hr}$ & Smooth file & 3 \\
& Rough file & 4 \\
Carburized at $950^{\circ} \mathrm{C} \&$ soaked for $1.50 \mathrm{hr}$ & Medium file & 3 \\
& Smooth file & 3 \\
\hline
\end{tabular}

Note. Assignment of test result very high $=7$, high $=6$, medium $=5$, low $=4$, very low $=3$, little $=2$, very little $=1$, no action $=0$

As shown in graph fig 15, it was observed that when the steel sample was tested with the abrasive file before carburization the loose or remove (the abrasion action) very high in another way have high weight loss. When the material is treated after carburization the scratching action decreased, the best abrasive resistivity is observed for the steel samples that were carburized at $950{ }^{\circ} \mathrm{C}$ for all of the abrasive files even though the scratching action was different for different abrasive file means the weight loss at this carburization temperature is very low. For example, when the material is treated with the rough file the scratching action (weight lose) decreased as the material was carburized at 950 ${ }^{\circ} \mathrm{C}$. When the steel sample that was carburized at a temperature of $950{ }^{\circ} \mathrm{C}$ is treated with smooth abrasive file the scratching action (weight lose) almost negligible.

Generally, for all samples the results of abrasive wear test roughly speaking the weight loss during abrasion for all of the carburized steel samples decrease linearly with increase in hardness or with increase in the carburization temperature. The highest weight loss was observed for the uncarburized steel samples and the lost for the steel sample that were carburized at $950{ }^{\circ} \mathrm{C}$. This results is also supported from the literature [24].

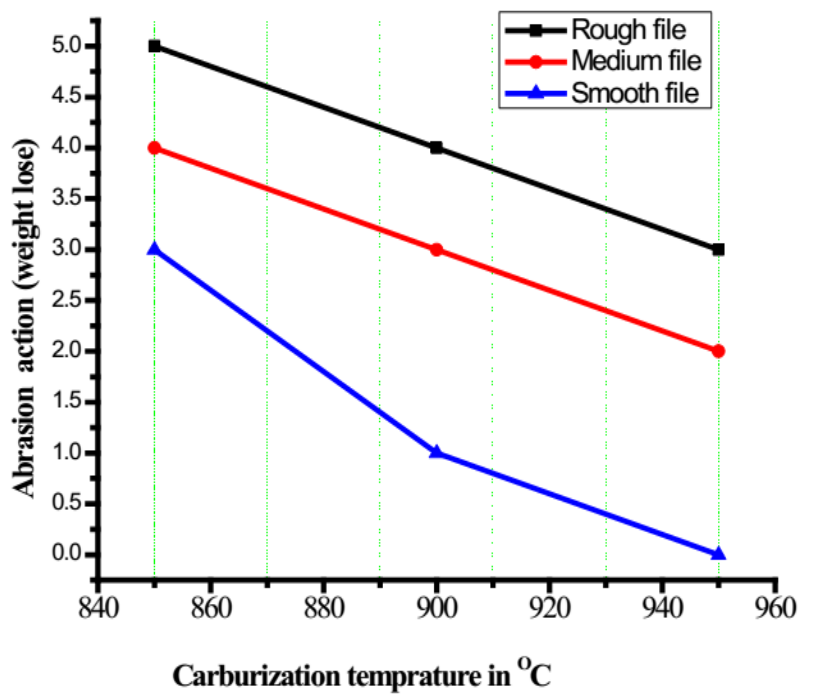

Fig. 15. The effect of carburization temperature on the abrasive wear resistance. 


\section{Conclusions}

From the various results obtained during the experimental work it can be concluded that the mechanical and wear characteristics of the traditional farm implements strongly influenced by the carburization temperature and carburization process. Hence depending upon the properties and applications required we should go for a suitable heat treatment processes. The pack carburization process and water quenching after carburization improve the mechanical properties and wear resistance like hardness, tensile strength and, abrasive wear resistance of the steel samples and

The carburization process decreases the impact energy (toughness) of the steel samples. In addition, the toughness is decreases with increase in the carburization temperature. The sample carburized at $950{ }^{\circ} \mathrm{C}$ soaked for 1.50 hours followed by water quenching are considered better because it showed a trend of hard case with softer core. The pack carburization process followed by water quenching exhibit a better combination of hardness, ultimate tensile strength (tensile strength) and abrasive wear resistance of the steel samples.

The hardness, tensile strength (UTS), percent elongation, percent reduction in area, modulus of elasticity increases as the carburizing temperature increases. The weights lose due to abrasion decreases as the carburization temperature an increase this is because of the surface of steel sample becomes harden by the carburization process.

\section{Acknowledgements}

I would like to carry my gratitude to Ethiopian Defense Engineering Collage Department of metallurgy and material engineering for allowing me to conduct my laboratory work. I would also like to pass my gratitude to Kotebe Metal Tools Factory for providing me the necessary laboratory samples. In addition, I would like to thank the laboratory technician of Defense Engineering College and staff members of physics department Hawassa University and to my Friends for their encouragement.

\section{References}

[1] Kumar Chawla, Mechanical Behavior of Materials, $2^{\text {nd }}$ edition, Published in the United States of America by Cambridge University Press, New York, 2008, pp 886.

[2] Encyclopedia Britannica, Materials testing, Encyclopedia Britannica Ultimate reference Suite Chicago: Encyclopedia Britannica, 2012, pp39-42.

[3] Krauss G. Principles of Heat Treatment of Steel, American Society for Metals, Vol.1, Ohio, 1980, PP 50-251.

[4] B. Selcuk, M.B. Karamıs, V. Kuzucu, An investigation on surface properties of treated low carbon and alloyed steel (boarding and carburizing),J. Mater Process,2000,pp 310-317.

[5] Benscoter, A. O. and Bramfitt, B. L., Metallographer's Guide, Practices and Procedures for Irons and Steels,ASMInternational,MaterialsPark,Ohio,USA,2002,pp761.
[6] Ward D.M., Influence of carburization on the properties of furnace tube alloys, in Corrosion and Mechanical Strength at High Temperatures Guttmann, and Merz, M. (Eds.), Applied Science Publishers, Ltd., London, 1981, p. 71-83.

[7] Izciler M. and Tabur M., Abrasive wear behavior of different case depth gas carburized AISI gear steel, wear, 2006, pp1-9.

[8] Yang C. F.,Chiu L. H. and Wu J. K., Effect of carburization and hydrogenation on the impact toughness of AISI 4118 steel, surface and coating technology, 1995, pp18 - 22.

[9] G.E. Dieter, Introduction to Ductility, in Ductility, American Society for Metals, 1968, pp 766.

[10] William D. Callister, JR, Fundamentals of Materials Science and Engineering, Salt Lake City, Utah, John Wiley and Sons, August 2000,pp975.

[11] Michael L.Wayman, John E.Bringas, CASTI metals black book European ferrous data,2nd edition, John E. Bringas, Edmonton, Alberta, 1953,pp164.

[12] Althouse, Andrew D., Carl H. Turnquist, and William A. Bowditch, Modern Welding, Goodheart-Wilcox Co.Inc., 1970,pp1-192.

[13] Kay Geels, Daniel B. Fowler, Wolf-Ulrich Kopp, and Michael Rückert Metallographic and Material graphic specimen preparation, light microscopy, image analysis and hardness testing, ASTM International, West Conshohocken,2007,pp 761.

[14] James E. House, Inorganic Chemistry, Academic Press is an imprint of Elsevier, London, 2008, pp 375-380.

[15] Krauss G. Principles of Heat Treatment of Steel, American Society for Metals, Vol.1, Ohio, 1980, PP 50-25.

[16] Izciler M. and Tabur M., Abrasive wear behavior of different case depth gas carburized AISI gear steel, wear, 2006, pp1-9.

[17] Yang C. F.,Chiu L. H. and Wu J. K., Effect of carburization and hydrogenation on the impact toughness of AISI 4118 steel, surface and coating technology, 1995, pp18 - 22.

[18] ASM Handbook Committee, Mechanical Testing and Evaluation, vol.8, ASM International, USA, 2000, pp 2235.

[19] Higgins R.A., Engineering Metallurgy Part 1: Applied Physical Metallurgy,5th edition ELBS with Edward Arnold, Kent, 1991,pp1-23.

[20] American Society of Mechanical Engineers ,International Conference on Fatigue of Metals, Institution of Mechanical Engineers, London, and American Society of Mechanical Engineers, New York, 1956,pp1125.

[21] Dieter G. E., Mechanical Metallurgy, 3rd edit ion, McGraw Hills, Singapore, 1988, pp 766.

[22] Marc André Meyers, Krishan, Mechanical behavior of materials, Cambridge University of press, New York, 2008, PP882.

[23] Luo Q., Xie J. and Song Y., Effects of microstructure on the abrasive wear behavior of spheroidal cast iron, Wear, 1995.pp1-8.

[24] Akdemir A., Kus R. and Simsir M., Impact toughness and microstructure of continuous steel wire reinforced cast iron composite, Material science and Engineering, 2009,pp1-7. 
[25] Ward D.M., Influence of carburization on the properties of furnace tube alloys, In: Corrosion and Mechanical Strength at High Temperatures Guttmann, and Merz, M. (Eds.), Applied Science Publishers, Ltd., London, 1981, p. 71-83.

[26] G.L. Huyett, Engineering Handbook, 26th edition, Industrial Press, Inc. of New York, NY, 2000, pp 4-95.
[27] T.VRajan, C.P Sharma, Ashok Sharma, Heat Treatment: Principles and Techniques, 1987,1-14.

[28] MohdMarhan, BinAsari, a study on heat treatment of carburizing carbon steel, unpublished, December 2010,pp 39. 